\title{
Increased risk and early onset of ALS in professional players from Italian soccer teams
}

Elisabetta Pupillo PharmD ${ }^{1}$, Elisa Bianchi $\mathrm{MSc}^{1}$, Nicola Vanacore $\mathrm{MD}^{2}$, Carla Montalto PharmD ${ }^{1}$, Giuseppe Ricca PharmD ${ }^{1}$, Francesco Saverio Robustelli della Cuna PharmD ${ }^{3}$, Fabio Fumagalli PharmD ${ }^{4}$, Massimiliano Castellani $\mathrm{MSc}^{5}$, Ettore Beghi $\mathrm{MD}^{* 1}$ and Union of Professional Football Players in Italy.

1 Istituto di Ricerche Farmacologiche Mario Negri IRCCS, Milano, Italy;

2 Centro Nazionale Prevenzione delle Malattie e Promozione della Salute, Istituto Superiore di Sanità, Roma, Italy;

3 Department of Drug Science, University of Pavia, Pavia, Italy;

4 Department of Pharmacological and Biomolecular Sciences, Università degli Studi di Milano, Milano, Italy;

5 Avvenire Nuova Editoriale Italiana, Milano, Italy.

Search Terms: Cohort studies [54]; Incidence studies [57]; Risk factors in epidemiology [59]; Amyotrophic lateral sclerosis [178].

Publication History: This manuscript has not previously published.

Submission Type: Article

Title Character count: $\mathbf{6 8}$

Number of Tables: 2

Word count of Abstract: $\mathbf{2 5 0}$

Word count of Paper: 3136

Supplemental material: Supplemental Table e-1, Supplemental Table e-2 (available online) 


\section{* Corresponding author:}

Ettore Beghi, MD

Laboratory of Neurological Disorders, Istituto di Ricerche Farmacologiche Mario Negri IRCCS, Via Mario Negri 2, 20156 Milan, Italy.

Tel: +390239014542; Fax: +390239001916

email: ettore.beghi@marionegri.it

https://orcid.org/0000-0003-2542-0469

Elisabetta Pupillo elisabetta.pupillo@marionegri.it

Elisa Bianchi elisa.bianchi@,marionegri.it

Nicola Vanacore nicola.vanacore@iss.it

Carla Montalto carlamontalto93@, libero.it

Giuseppe Ricca peppericca@live.it

Francesco Saverio Robustelli della Cuna fsaveriorobustelli@unipv.it

Fabio Fumagalli fabio.fumagalli@unimi.it

Massimo Castellanim.castellani@avvenire.it

Ettore Beghi ettore.beghi@marionegri.it

\section{Financial Disclosures:}

Elisabetta Pupillo - Reports no disclosures

Elisa Bianchi - Reports no disclosures

Carla Montalto - Reports no disclosures

Giuseppe Ricca - Reports no disclosures

Nicola Vanacore - Reports no disclosures

Francesco Saverio Robustelli della Cuna- Reports no disclosures

Fabio Fumagalli- Reports no disclosures

Massimo Castellani- Reports no disclosures

Ettore Beghi reports grants from the Italian Ministry of Health and grants from SOBI Pharma

Company during the conduct of the study. 
Statistical Analysis: Statistical analysis was performed by one of the authors (Elisa Bianchi).

Study Funded: The study was supported by the Istituto di Ricerche Farmacologiche Mario Negri IRCCS. 


\begin{abstract}
Objective: Since the observation of several deaths from amyotrophic lateral sclerosis (ALS) among Italian professional soccer players, an association between ALS and soccer has been postulated. The objective of the study is to investigate the association between professional soccer and the risk of ALS in a large cohort of former professional soccer players with prolonged follow-up.
\end{abstract}

Methods: All professional soccer players practicing in the period 1959-2000 were identified through the archives of an Italian soccer cards publisher. For each player, date and place of birth, playing role and team history were recorded. Each player was followed since 15 years of age. Incident ALS cases were all soccer players first diagnosed during the period 1959-2018. The expected incidence rate was the number of ALS cases/100,000 person-years expected in the cohort. SIR was the ratio between observed and expected incidence rate.

Results: 34 ALS cases were detected. The number of expected cases was 17.8. The SIR was 1.91 (95\% CI 1.32-2.67) in the entire sample and 4.66 (95\% CI 2.66-7.57) in subjects aged less than 45 years. The mean age at diagnosis was 45.0 years. Compared to the mean age of onset of ALS in the general population (65.2 years), the disease in former soccer players occurred 20.2 years earlier.

Conclusions: Professional soccer players are at higher risk of developing ALS than the general population. Soccer players with ALS develop the disease at a younger than expected age. 


\section{Introduction}

Amyotrophic Lateral Sclerosis (ALS) is a rare neurodegenerative disease. ${ }^{1}$ The etiology of ALS is still unknown. A multifactorial origin is hypothesized resulting from the interplay between genetic and environmental factors. ${ }^{2}$

Soccer has been implicated in the past as a risk factor for ALS. Among 24,000 soccer players active from 1960 to 1996 in the three top leagues (A, B, C), eight cases who died with ALS were identified; the expected number of deaths for ALS was $0.69 .{ }^{3}$ A second study, investigating 7325 Italian professional soccer players active from 1970 to 2001 in the A and B leagues, identified 5 ALS cases vs 0.77 expected. ${ }^{4}$ These findings were confirmed in an extended cohort study by the same group (Chiò et al, 2009). The affected players were younger than the ALS patients in the general population. Those studies were performed using data from a legal investigation on the possible association between substance abuse among soccer players. Recent published books pointed out the attention to soccer players diagnosed with ALS in more recent years. ${ }^{5,6}$ No studies verified the incidence of ALS in former soccer players with a long follow up period. In addition, published reports have been thought to be methodologically flawed due to incorrect analysis of the data. ${ }^{7}$ For these reasons, the relationship between ALS and soccer needed to be further investigated. On this background, we carried out a new study with the aim to quantify the risk of ALS in a wider well-structured cohort of former professional soccer players with longer follow up.

\section{Methods}

We identified all male professional soccer players included in the three Italian professional soccer leagues (A, First division, B, Second division, C, Third division) from September 1st 1959 (season 1959/1960) to June 30th 2000 (season 1999/2000). The inclusion of soccer players in the first, second or third division depends only on their playing ability and is unrelated to the age or the duration of the professional activity. To assemble the study cohort, we used the annual almanacs 
published by the Panini Company, an Italian soccer cards publisher. ${ }^{8}$ In the almanacs, each team is depicted in a list showing all players'names along with playing role (goalkeeper, back, midfielder, forward), and league. Date and place of birth of players were also recorded. Data related to each single player were collected for the duration of the professional activity. A professional soccer player was considered exposed when starting the activity by 15 years of age, as established by the Union of Professional Football Players in Italy, because strenuous physical exercise generally starts at a median age of 15 years.

All ALS cases were identified using different sources: 1. Google web site: we used several key words in order to identify all soccer players affected by ALS: "Frontotemporal dementia", "Neurodegeneration", "Neurodegenerative disease", "Motor neuron disease and soccer", "Motor neuron disease and soccer players". All words were spelled both in Italian and English language. Using Google search, we checked 20 pages for each key word. The name and surname, date of diagnosis of ALS, date of death, and number of news reporting the same information were recorded; 2. Two published books related to ALS and soccer in Italian teams: "SLA. Il male oscuro del pallone" and "Il morbo del pallone. Gehrig e le sue vittime" written by one of the authors., The author interviewed at least one family member for each soccer player with ALS in order to collect detailed disease information; 3. A recent scientific report: “Amyotrophic Lateral Sclerosis and soccer: an internet survey of 29 Italian players". 9

The diagnosis was confirmed if the player's and the disease name were present in at least two unrelated sources. In addition, detailed medical records were collected for 18 cases.

Descriptive statistics were performed for the available demographical and exposure variables: year of birth, year of start of professional activity (set at 15 years for all players), first playing role (role played during the first season in one of the professional leagues), main playing role (role in which the player spent the majority of seasons during the study period), and main league (league in which the player spent the majority of seasons during the study period). All players who played for at least one year in the Italian professional leagues (A, B and C) between 1959 and 2000 (from 1959/1960 
to $1999 / 2000$ playing season) were included in the exposed cohort. The cohort was followed retrospectively from the start of exposure until December 31 2018. During this period, ALS cases were identified, along with the year of death and the year of diagnosis, when available. The mean disease duration (defined as time from diagnosis to death) in years was estimated among players for whom both the year of diagnosis and the year of death were available. For players without the year of diagnosis, this was set at the mean estimated number of years of disease duration (of ALS cases as described above) prior to death. Incidence rates of ALS were calculated in the entire exposed cohort and in different categories defined according to age ( $\leq 45$ years, $45-54$ years, $55-64$ years, 65 74 years, $75+$ years $)$, year of start of professional activity $(\leq 1965,1965-1974,1975-1984, \geq 1985)$, main playing role, and main league. Since detailed data on mortality were not available, the total amount of person-years at risk of developing ALS cumulated by the cohort was estimated using the expected mortality in the general Italian male population (DEMO-ISTAT mortality data). ${ }^{10}$ Mortality data in the general population (DEMO-ISTAT) ${ }^{9}$ were available starting from the year 1975. For this reason, all players entering in the exposed cohort before the year 1975 were assumed to be alive until this year (this assumption is adequate because the first player entered in the cohort in the year 1937 was 53 years old in 1975). The total amount of person-years cumulated until 1975 was calculated as the sum of the number of years of follow-up of each player, from entry in the cohort until the year 1975, and was partitioned by year of age. The total amount of person-years cumulated from 1975 to 2018 was estimated partitioning the total number of players in the cohort by year of age (from 15 to 53 years) in the year 1975, and then multiplying the number of players in each age by the prospective probability of survival for an individual of that age (the probability that a subject of age $\mathrm{x}$ would survive until the subsequent year, reaching age $\mathrm{x}+1$ ), in order to obtain the estimated number of players still alive in the subsequent year (1976) by age (from 16 to 54 years). As all subjects who reached age 15 years in 1976 entered the cohort in that year, the number of these subjects was added to the total amount of person-years cumulated during the year 1976, which, at this point, resulted partitioned by age from 15 to 54 years. The process was iterated until 
the year 2018, leading to the estimation of the expected total number of players by age in each year from 1975 to 2018 . The total number of person-years by age and year was then summed during the 44-year period in order to obtain the total amount of person-years by age cumulated by the cohort during the entire study period. The expected incidence rate for ALS in the cohort of exposed subjects was estimated using the incidence of ALS in males in the Lombardy region, Northern Italy, during the years $1998-2002$ as reference. ${ }^{11}$ Expected incidence rates by age categories $(\leq 45$ years, 45-54 years, 55-64 years, 65-74 years, 75+ years) were applied to the total amount of person-years, partitioned by age, cumulated by the cohort of soccer players, to obtain the expected number of cases in each age category. The total expected incidence rate was then calculated as the sum of the expected cases in each age category divided by the total amount of person-years cumulated by the cohort. The observed number of cases (or, equivalently, the observed incidence rate) was then compared to the expected number of cases (or, equivalently, the expected incidence rate)

calculating the standardized incidence ratio (SIR), with $95 \%$ confidence interval $(95 \% \mathrm{CI})$. The SIR is the ratio between observed and expected number of cases, or, equivalently, the ratio between observed and expected incidence rate. The number of observed and expected cases, the observed and expected incidence rates, and the SIR with $95 \%$ CI were calculated in the whole cohort and by age, year of start of professional activity, main playing role, main league, and team. The total person-years of a team is given by the sum of the person-years of each player who played for at least 1 season in that team.

The mean estimated age at diagnosis (with standard deviation) was calculated among soccer players who developed ALS during the study period, and compared to the mean age of diagnosis in the general population with the t-test, using the mean age of diagnosis in Europe as reference. ${ }^{12}$ The study did not receive any funding. As the data sources are publicly available, IRB/EC and ethical approval were not required. 


\section{Data Availability Statement}

Anonymized data will be shared by request from any qualified investigator.

\section{Results}

The total number of players included in the cohort was 23,586, who were followed for $1,001,318$ person-years. A description of the cohort is given in Table 1. During the study period, 34 ALS cases were identified. Table 2 depicts the total amount of person-years at risk of developing ALS cumulated by the cohort during the study period, the number of observed and expected cases, the observed and expected incidence rates, and the SIR with 95\% CI, in the whole cohort and stratified by age, year of start of professional activity, main playing role and main league. The number of observed cases was 1.91 times (95\% CI 1.32-2.67) higher than expected. The risk increase was highest among players younger than 45 years, with a SIR of 4.66 (95\% CI 2.66-7.57). The year of start of professional activity in which the increased risk peaked was between 1975 and 1984 (SIR 3.97; 95\% CI 1.91-7.31), followed by the period preceding the year 1965 (SIR 1.76; 95\% CI 1.052.79). The playing role showing the greatest risk increase was the midfielder (SIR 2.37; 95\% CI 1.32-3.90). The first division (A) carried the highest risk increase, with a SIR of 5.69 (95\% CI 2.7310.47) followed by the second (B), with a SIR of 2.79 (95\% CI 1.12-5.74). No differences were found across teams (Supplemental Table e-1), as all the confidence intervals overlap. The median age at diagnosis among 554 men with ALS in Europe ${ }^{12}$ was 65.2 years (interquartile range 56.0-72.2). In the cohort of soccer players, the mean age at diagnosis was estimated at 45.0 years (standard deviation 12.6). Assuming a normal distribution, the mean age at diagnosis in Europe is equal to the median (65.2 years) and the standard deviation is 12 (approximately the interquartile distance, 16.2, divided by 1.35). Therefore, the mean age at diagnosis in soccer players was estimated to be 20.2 years earlier than in the general population $(\mathrm{p}<0.0001$, $t$-test).

\section{Discussion}


To our knowledge, this is the first study evaluating the relationship between professional soccer and ALS with a long follow up period, from 1959 to 2018. Our findings are in line with previous reports in Italian soccer players (Supplemental Table e-2) but show a comparatively lower risk. The difference can be explained by the length of follow-up. As the risk of ALS has been found to peak in the youngest age categories in soccer players, while in the general population the incidence of the disease tends to increase with age, we can assume that, prolonging follow-up, the difference between observed and expected cases tends to decrease. This leads to a more realistic measure of the relative risk, without excluding a significant association.

Several factors can be implicated as risk factors for ALS in professional soccer players. Some can be part of the soccer activity, like traumatic events. Soccer is a "contact sport", where players can hit each other several times in a match. This means that players experience several injuries during the entire professional activity. It has been established that traumatic events are risk factors for $\mathrm{ALS}^{13}$ as reported in Italian ${ }^{14}$ and European ${ }^{15}$ case-control studies.

The hypothesis that strenuous physical activity could be a risk factor for developing ALS was also explored but with inconclusive results. While several case-control studies have suggested an association between leisure or moderate physical activity, ${ }^{16-19}$ work-related physical activity ${ }^{17}$ and professional physical activity, ${ }^{17,20-25}$ others have not. ${ }^{26-28}$ These apparently discrepant results could be explained by the differing definition of exposure and the assessment of differing levels of physical activity. In a recent study using linkage disequilibrium score regression and Mendelian randomization techniques (Bandres-Ciga et al, 2019), light physical activity was inversely associated with the risk of ALS while intensive physical activity carried a higher disease risk. Data reported in a European population based case-control study showed a significant association between physical activity (work-related or sport-related) and an earlier age at onset of the symptoms of the disease, ${ }^{26}$ with a median age at symptoms onset of 61.5 years vs. 67.1 years in those never performing physical activity. A younger age at disease onset was found by others in soccer players 
and also in people who performed other types of physical activity. ${ }^{23,29}$ In line with these findings, in our study former soccer players were diagnosed with ALS 20.2 years before the general population. Based on our findings and the present knowledge, we hypothesize that soccer players with ALS are susceptible individuals who develop the disease at a younger than expected age in response to combinations of environmental factors, including injuries and heavy physical activity. This hypothesis is supported by the present measure of the risk and the consistency of our data and the published reports on the earlier age at onset of the disease in this professional category.

We found a higher than expected incidence of ALS among soccer players in two separate periods (1975-84 and prior to 1965). In the absence of clear time trends or environmental factors that could explain clusters of ALS cases in these periods, the differences might be due to the small numbers and/or the arbitrary selection of the time intervals.

Midfielder was the most frequent role played by those who developed ALS. This observation is confirmed by a previous study. ${ }^{23}$ However, as midfielder is the most frequent role (more than $35 \%$ of our players), the power for reaching statistical significance is higher in this group than in others. Italian reporters emphasized the presence of ALS cases among subjects who played in few specific teams, claiming the role of some environmental factors such as the contamination of the soccer field by herbicides or cyanobacteria. ${ }^{30}$ This data was never verified because the number of detected cases in each team was too small. We had the chance to analyse all the teams including two or more ALS cases. No significant association between ALS and playing team was detected.

The excess risk of ALS is not restricted to the Italian soccer players. One published report outside Italy refers to a cluster of three cases who played in England. ${ }^{31}$ Due to this small number, the play of chance cannot be excluded. Another, recent study done in Scotland found ALS and other neurodegenerative diseases (Alzheimer's and Parkinson's disease) more commonly reported in death certificates of former professional soccer players than in the general population. ${ }^{32}$ These observations can provide the background for further studies in other European countries. 
An increased risk of ALS can be implicated also among professional players in other sports. A higher mortality due to ALS (Standardized Mortality Ratio, 4.04) was detected in a cohort of 3,439 US Football National League players (FNL). ${ }^{33}$ However, another study comparing NFL players with professional American baseball players found no significant differences between the two groups (Hazard Ratio 2.81; 95\% CI 0.75-10.51). ${ }^{34}$ In contrast, no excess cases were found among basketball players and road cyclists in an Italian study. ${ }^{23}$ However, the absence of ALS cases may be explained here by the small number of exposed individuals (basketball players, 1,973 , road cyclists, 1,701) and the short follow up (basketball, 35,273 person years; road cyclists, 63,346 person years).

Our study has limitations: 1 . The medical details on ALS diagnosis could be examined only in 18 cases; however, the investigation of multiple independent sources, the confirmation of the disease in all patients with available medical records, and the implications of this diagnosis make diagnostic errors unlikely; 2 . The age at diagnosis was not available in some cases and it was estimated using the mean disease duration from cases for which it was available. This could have influenced the estimated age at diagnosis reported here; however, given the marked difference with the general population, it is unlikely that our results are entirely biased by this imputation; 3 . Incidence rates used as reference for calculating the expected cases were obtained from a study conducted in the Lombardy region ${ }^{11}$ during the years 1998-2002, while our exposed cohort was made of individuals from all Italian regions, including players born in other countries (less than 17\%) and covered a different period of time (1959-2000). We cannot thus exclude that expected rates would have been different from those used here as reference; however, the expected rate calculated for the Lombard registry are in line with other Italian reports; 4. All ALS cases were identified by news, internet websites and books. An underestimation of cases may have occurred, particularly among players of the $\mathrm{C}$ leagues (less frequently followed by the media, especially after cessation of the activity). However, the increased use of internet makes information more easily available than in the past, making it improbable that so a devastating diagnosis would be reported only in famous soccer 
players; in addition, underascertainment of soccer players with late disease onset might reduce the present gap in the age of onset, but would contribute to increase the disease risk even further; 5 . The exact number of person-years cumulated by the cohort of exposed was not available in our data, and it was estimated assuming that all players entering the cohort before the year 1975 were alive until this year, and using the prospective probabilities of survival in Italian males for all subsequent years until 2018. ${ }^{10} \mathrm{We}$ cannot exclude that soccer players incur in mortality rates that differ from those of the general population. In case of higher (or lower) mortality rates in soccer players an overestimation (or underestimation) of expected cases may have occurred, with a consequent underestimation (or overestimation) of the SIR.

\section{Conclusions}

In conclusion, our findings show that professional soccer players are at increased risk of ALS, but the measure of the risk tends to decrease when prolonging follow-up; however, soccer players experience onset of ALS symptoms at a much younger than expected age. Repeated traumatic events and heavy physical exercise may be all implicated, but the role of genetic predisposition cannot be likewise excluded. 


\section{Aknowledgement}

The authors are very grateful to the Italian Union of Professional Football Players for data cleaning and verification; Roberto Vinciguerra for ALS case ascertainment; Rizzoli Corriere della Sera for providing access to Almanacchi Panini.

\section{Author Contributions}

Dr. Pupillo was the study coordinator, performed data collection, had full access to all the data in the study, took responsibility for the integrity of the data, and drafted the manuscript. Dr. Bianchi performed the data analysis, interpretation of data and participated to the draft of the manuscript. Dr. Vanacore and Dr. Beghi interpreted the data and performed a critical revision of the manuscript for intellectual contents. Dr. Montalto and Dr. Ricca participated in data collection and data entry. Dr. Robustelli della Cuna and Dr. Fumagalli participated to the revision of the manuscript. Dr. Castellani performed data cleaning and verification.

The Union of Professional Football Players in Italy performed data cleaning and verification. 


\section{References}

1. Marin B, Boumédiene F, Logroscino G, et al. Variation in worldwide incidence of amyotrophic lateral sclerosis: a meta-analysis. Int J Epidemiol 2017;46(1):57-74.

2. Al-Chalabi A, Hardiman O. The epidemiology of ALS: a conspiracy of genes, environment and time. Nat Rev Neurol 2013;9(11):617-628.

3. Belli S, Vanacore N. Proportionate mortality of Italian soccer players: is amyotrophic lateral sclerosis an occupational disease? Eur J Epidemiol 2005;20(3):237-242.

4. Chiò A, Benzi G, Dossena M, Mutani R, Mora G. Severely increate risk of amyotrophic lateral sclerosis among Italian professional football players. Brain 2005;128(Pt 3):472-476.

5. Castellani M, ed. Il morbo del pallone. Gehrig e le sue vittime. Torino:Bradipolibri; 2009.

6. Castellani M, ed. SLA. Il male oscuro del Pallone. Pisa: GoalBook; 2016.

7. Armon C. Sports and trauma in amyotrophic lateral sclerosis revisited. J Neurol Sci 2007;262(1-2):45-53.

8. http://collectibles.panini.it/store/col_ita it/almanacchi.html? $\mathrm{p}=1$

9. Vanacore N, Barbariol P, Caffari B, Lacorte E, Bacigalupo I, Spila Alegiani S. Amyotrophic Lateral Sclerosis and soccer: an internet survey of 29 Italian players. Ann Ist Super Sanita 2018;54(4):364-369.

10. http://demo.istat.it/

11. Beghi E, Millul A, Micheli A, Vitelli E, Logroscino G; SLALOM Group. Incidence of ALS in Lombardy, Italy. Neurology 2007;9;68(2):141-145.

12. Logroscino G, Traynor BJ, Hardiman O, et Al. Incidence of amyotrophic lateral sclerosis in Europe. J Neurol Neurosurg Psychiatry 2010;81(4):385-390.

13. Blecher R, Elliott MA, Yilmaz E, et al. Contact Sports as a Risk Factor for Amyotrophic Lateral Sclerosis: A Systematic Review. Global Spine J 2019;9(1):104-118.

14. Pupillo E, Messina P, Logroscino G, et Al. Trauma and amyotrophic lateral sclerosis: a casecontrol study from a population-based registry. Eur J Neurol 2012;19(12):1509-1517. 
15. Pupillo E, Poloni M, Bianchi E, et al. Trauma and amyotrophic lateral sclerosis: a european population-based case-control study from the EURALS consortium. Amyotroph Lateral Scler Frontotemporal Degener 2018;19(1-2):118-125.

16. Huisman MH, Seelen M, de Jong SW, et al. Lifetime physical activity and the risk of amyotrophic lateral sclerosis. J Neurol Neurosurg Psychiatry 2013;84(9):976-981.

17. Strickland D, Smith SA, Dolliff G, Goldman L, Roelofs RI. Physical activity, trauma, and ALS: a case-control study. Acta Neurol. Scand 1996;94(1):45-50.

18. Okamoto K, Kihira T, Kondo T, et Al. Lifestyle factors and risk of amyotrophic lateral sclerosis: a case-control study in Japan. Ann Epidemiol 2009;19(6):359-364.

19. Beghi E, Logroscino G, Chiò A, et al. Amyotrophic lateral sclerosis, physical exercise, trauma and sports: Results of a population-based pilot case-control study. Amyotroph Lateral Scler 2010; 11(3):289-292.

20. Lehman EJ, Hein MJ, Baron SL, Gersic CM. Neurodegenerative causes of death among retired National Football League players. Neurology 2012;79(19):1970-1974.

21. Abel EL. Football increases the risk for Lou Gehrig's disease, amyotrophic lateral sclerosis. Percept Mot Skills 2007;104(3 Pt 2):1251-1254.

22. Taioli E. Use of permitted drugs in Italian professional soccer players. Br J Sports Med 2007;41(7):439-441.

23. Chio A, Calvo A, Dossena M, Ghiglione P, Mutani R, Mora G. ALS in Italian professional soccer players: the risk is still present and could be soccer-specific. Amyotroph Lateral Scler 2009;10(4):205-209.

24. Longstreth WT, McGuire V, Koepsell TD, Wang Y, van Belle G. Risk of amyotrophic lateral sclerosis and history of physical activity: a population-based case-control study. Arch Neurol 1998;55(2):201-206.

25. Scarmeas N, Shih T, Stern Y, Ottman R, Rowland LP. Premorbid weight, body mass, and varsity athletics in ALS. Neurology 2002;59(5):773-775. 
26. Pupillo E, Messina P, Logroscino G, Beghi E; SLALOM Group. Long-term survival in amyotrophic lateral sclerosis: a population-based study. Ann Neurol 2014;75(2):287-297.

27. Vanacore N, Cocco P, Fadda D, Dosemeci M. Job strain, hypoxia and risk of amyotrophic lateral sclerosis: Results from a death certificate study. Amyotroph Lateral Scler 2010;11(5):430434.

28. Valenti M, Pontieri FE, Conti F, Altobelli E, Manzoni T, Frati L. Amyotrophic lateral sclerosis and sports: a case-control study. Eur J Neurol 2005;12(3):223-225.

29. Chiò A, Mora G, Moglia C, et al. Secular trends of Amyotrophic Lateral Sclerosis. The Piemonte and Valle d'Aosta Register. JAMA Neurol 2017;74(9):1097-1104.

30. Stipa G, Taiuti R, de Scisciolo G, et al. Sporadic amyotrophic lateral sclerosis as an infectious disease: a possible role of cyanobacteria? Med Hypotheses 2006;67(6):1363-1371.

31. Wicks P, Ganesalingham J, Collin C, Prevett M, Leigh NP, Al-Chalabi A. Three soccer playing friends with simultaneous amyotrophic lateral sclerosis. Amyotroph Lateral Scler 2007;8(3):177179.

32. Mackay DF, Russell ER, Stewart K, MacLean JA, Pell JP, Stewart W. Neurodegenerative Disease Mortality among Former Professional Soccer Players. N Engl J Med 2019 Oct 21. [Epub ahead of print]

33. Lehman EJ, Hein MJ, Baron SL, Gersic CM. Neurodegenerative causes of death among retired National Football League players. Neurology 2012;79(19):1970-1974.

34. Nguyen T, Zafonte RD, Chen JT, et al. Mortality Among Professional American-Style Football Players and Professional American Baseball Players. JAMA Network Open 2019;2(5):e194223. 
Table 1. General characteristics of 23,586 former soccer players

\begin{tabular}{|c|c|c|}
\hline & $\mathbf{N}$ & $\%$ \\
\hline \multicolumn{3}{|l|}{ Year of birth } \\
\hline$<1950$ & 6543 & 27.7 \\
\hline 1950-1959 & 4837 & 20.5 \\
\hline 1960-1969 & 6441 & 27.3 \\
\hline$\geq 1970$ & 5765 & 24.4 \\
\hline \multicolumn{3}{|c|}{$\begin{array}{l}\text { Year of start of } \\
\text { professional activity }\end{array}$} \\
\hline$<1965$ & 6543 & 27.7 \\
\hline $1965-1974$ & 4837 & 20.5 \\
\hline $1975-1984$ & 6441 & 27.3 \\
\hline 1985-1999 & 5765 & 24.4 \\
\hline \multicolumn{3}{|c|}{ First* playing role } \\
\hline Forward & 5534 & 23.5 \\
\hline Midfielder & 8531 & 36.2 \\
\hline Back & 6543 & 27.7 \\
\hline Goalkeeper & 2673 & 11.3 \\
\hline Not available & 305 & 1.3 \\
\hline \multicolumn{3}{|c|}{ Main** playing role } \\
\hline Forward & 5500 & 23.3 \\
\hline Midfielder & 8431 & 35.7 \\
\hline Back & 6853 & 29.1 \\
\hline Goalkeeper & 2679 & 11.4 \\
\hline Not available & 123 & 0.5 \\
\hline \multicolumn{3}{|c|}{ Main league $* * *$} \\
\hline A & 1974 & 8.4 \\
\hline B & 2582 & 10.9 \\
\hline $\mathrm{C}$ & 19030 & 80.7 \\
\hline
\end{tabular}

*The playing role at the first season in which the player appeared in the professional league during the study period.

**The playing role in which the player spent the majority of seasons during the study period.

***The league in which the player spent the majority of seasons during the study period. 
Table 2. Person-years of exposure, expected rates and number of cases, observed rates and number cases, and standardized incidence ratios with $95 \%$ confidence intervals

\begin{tabular}{|c|c|c|c|c|c|c|c|c|}
\hline & Person-years & $\begin{array}{l}\text { Expected rate } \\
\text { (per } 100,000)\end{array}$ & $\begin{array}{l}\text { Expected } \\
\text { cases }\end{array}$ & $\begin{array}{l}\text { Observed rate } \\
\text { (per 100,000) }\end{array}$ & $\begin{array}{l}\text { Observed } \\
\text { cases }\end{array}$ & SIR & $\begin{array}{l}95 \% \\
\text { LCL }\end{array}$ & $\begin{array}{l}95 \% \\
\text { UCL }\end{array}$ \\
\hline Total cohort & 1001318 & 1.78 & 17.8 & 3.39 & 34 & 1.91 & 1.32 & 2.67 \\
\hline \multicolumn{9}{|l|}{ Age } \\
\hline$<45$ years & 686767 & 0.50 & 3.4 & 2.33 & 16 & 4.66 & 2.66 & 7.57 \\
\hline $45-54$ years & 161771 & 2.70 & 4.4 & 5.56 & 9 & 2.06 & 0.94 & 3.91 \\
\hline $55-64$ years & 95806 & 6.20 & 5.9 & 7.30 & 7 & 1.18 & 0.47 & 2.43 \\
\hline $65-74$ years & 45611 & 7.20 & 3.3 & 4.38 & 2 & 0.61 & 0.07 & 2.20 \\
\hline $75+$ years & 11363 & 6.70 & 0.8 & - & - & - & - & - \\
\hline \multicolumn{9}{|c|}{$\begin{array}{l}\text { Year of start of } \\
\text { professional activity }\end{array}$} \\
\hline$<1965$ & 371912 & 2.74 & 10.2 & 4.84 & 18 & 1.76 & 1.05 & 2.79 \\
\hline 1965-1974 & 225075 & 1.86 & 4.2 & 2.22 & 5 & 1.20 & 0.39 & 2.79 \\
\hline 1975-1984 & 243136 & 1.03 & 2.5 & 4.11 & 10 & 3.97 & 1.91 & 7.31 \\
\hline 1985-1999 & 161195 & 0.55 & 0.9 & 0.62 & 1 & 1.13 & 0.03 & 6.29 \\
\hline \multicolumn{9}{|c|}{ Main* playing role } \\
\hline Forward & 236884 & 1.83 & 4.3 & 2.96 & 7 & 1.61 & 0.65 & 3.32 \\
\hline Midfielder & 357739 & 1.77 & 6.3 & 4.19 & 15 & 2.37 & 1.32 & 3.90 \\
\hline Back & 286472 & 1.72 & 4.9 & 3.14 & 9 & 1.82 & 0.83 & 3.46 \\
\hline Goalkeeper & 115409 & 1.82 & 2.1 & 2.60 & 3 & 1.43 & 0.29 & 4.16 \\
\hline \multicolumn{9}{|c|}{ Main league** } \\
\hline A & 88253 & 1.99 & 1.8 & 11.33 & 10 & 5.69 & 2.73 & 10.47 \\
\hline B & 118841 & 2.11 & 2.5 & 5.89 & 7 & 2.79 & 1.12 & 5.74 \\
\hline $\mathrm{C}$ & 794224 & 1.70 & 13.5 & 2.14 & 17 & 1.26 & 0.73 & 2.01 \\
\hline
\end{tabular}

$\overline{\mathrm{SIR}}=$ standardized incidence ratio; $\mathrm{LCL}=$ lower confidence limit; $\mathrm{UCL}=$ upper confidence limit.

*The playing role in which the player spent the majority of seasons during the study period.

**The league in which the player spent the majority of seasons during the study period. 
Appendix 1. Authors

\begin{tabular}{|l|l|l|l|}
\hline Name & Location & Role & Contribution \\
\hline $\begin{array}{l}\text { Elisabetta Pupillo } \\
\text { PharmD }\end{array}$ & $\begin{array}{l}\text { Istituto Mario Negri } \\
\text { IRCCS, Milano }\end{array}$ & Author & $\begin{array}{l}\text { Study coordinator, data collection, } \\
\text { responsible of the integrity of the } \\
\text { data, drafted the manuscript }\end{array}$ \\
\hline Elisa Bianchi MSc & $\begin{array}{l}\text { Istituto Mario Negri } \\
\text { IRCCS, Milano }\end{array}$ & Author & $\begin{array}{l}\text { Statistical analysis, interpretation of } \\
\text { data, drafted the manuscript }\end{array}$ \\
\hline Nicola Vanacore MD & $\begin{array}{l}\text { Istituto Superiore di } \\
\text { Sanità, Roma }\end{array}$ & Author & $\begin{array}{l}\text { Interpreted the data and performed } \\
\text { a critical revision of the manuscript }\end{array}$ \\
\hline $\begin{array}{l}\text { Carla Montalto } \\
\text { PharmD }\end{array}$ & $\begin{array}{l}\text { Istituto Mario Negri } \\
\text { IRCCS, Milano }\end{array}$ & Author & Data collection and data entry \\
\hline $\begin{array}{l}\text { Giuseppe Ricca } \\
\text { PharmD }\end{array}$ & $\begin{array}{l}\text { Istituto Mario Negri } \\
\text { IRCCS, Milano }\end{array}$ & Author & Data collection and data entry \\
\hline $\begin{array}{l}\text { Francesco Saverio } \\
\text { Robustelli della Cuna } \\
\text { PharmD }\end{array}$ & $\begin{array}{l}\text { Università di Pavia, } \\
\text { Pavia }\end{array}$ & Author & Revision of manuscript \\
\hline $\begin{array}{l}\text { Fabio Fumagalli } \\
\text { PharmD }\end{array}$ & $\begin{array}{l}\text { Università degli Studi } \\
\text { di Milano, Milano }\end{array}$ & Author & Revision of manuscript \\
\hline $\begin{array}{l}\text { Massimiliano } \\
\text { Castellani MSc }\end{array}$ & $\begin{array}{l}\text { Avvenire Nuova } \\
\text { Editoriale Italiana, } \\
\text { Milano }\end{array}$ & Author & Data cleaning and verification \\
\hline Ettore Beghi MD & $\begin{array}{l}\text { Istituto Mario Negri } \\
\text { IRCCS, Milano }\end{array}$ & Author & $\begin{array}{l}\text { Interpreted the data and performed } \\
\text { a critical revision of the manuscript }\end{array}$ \\
\hline
\end{tabular}




\section{Appendix 2. Co-Investigators}

The Union of Professional Football Players, the Italian association of soccer players, is a coinvestigator. It is the Italian association of football players. Several people of the executive team were involved in data cleaning and verification. The list of all the members of the association cannot be shared. 